\title{
Retrospective cohort study: Clinical presentation and outcomes of pre-eclampsia and eclampsia at Kenyatta National Hospital, Nairobi, Kenya
}

Charity Ndwiga

Population Council

Alfred Osoti

Pooja Sripad

Population Council

George Odwe

Population Council

Omondi Ogutu

See next page for additional authors

Follow this and additional works at: https://knowledgecommons.popcouncil.org/departments_sbsr-rh

Part of the Demography, Population, and Ecology Commons, Family, Life Course, and Society Commons, International Public Health Commons, Maternal and Child Health Commons, and the Medicine and Health Commons

How does access to this work benefit you? Let us know!

\section{Recommended Citation}

Ndwiga, Charity, Alfred Osoti, Pooja Sripad, George Odwe, Omondi Ogutu, and Charlotte E. Warren. 2018.

"Retrospective cohort study: Clinical presentation and outcomes of pre-eclampsia and eclampsia at Kenyatta National Hospital, Nairobi, Kenya," Ending Eclampsia Final Study Report. Washington, DC:

Population Council. 


\section{Authors}

Charity Ndwiga, Alfred Osoti, Pooja Sripad, George Odwe, Omondi Ogutu, and Charlotte E. Warren 


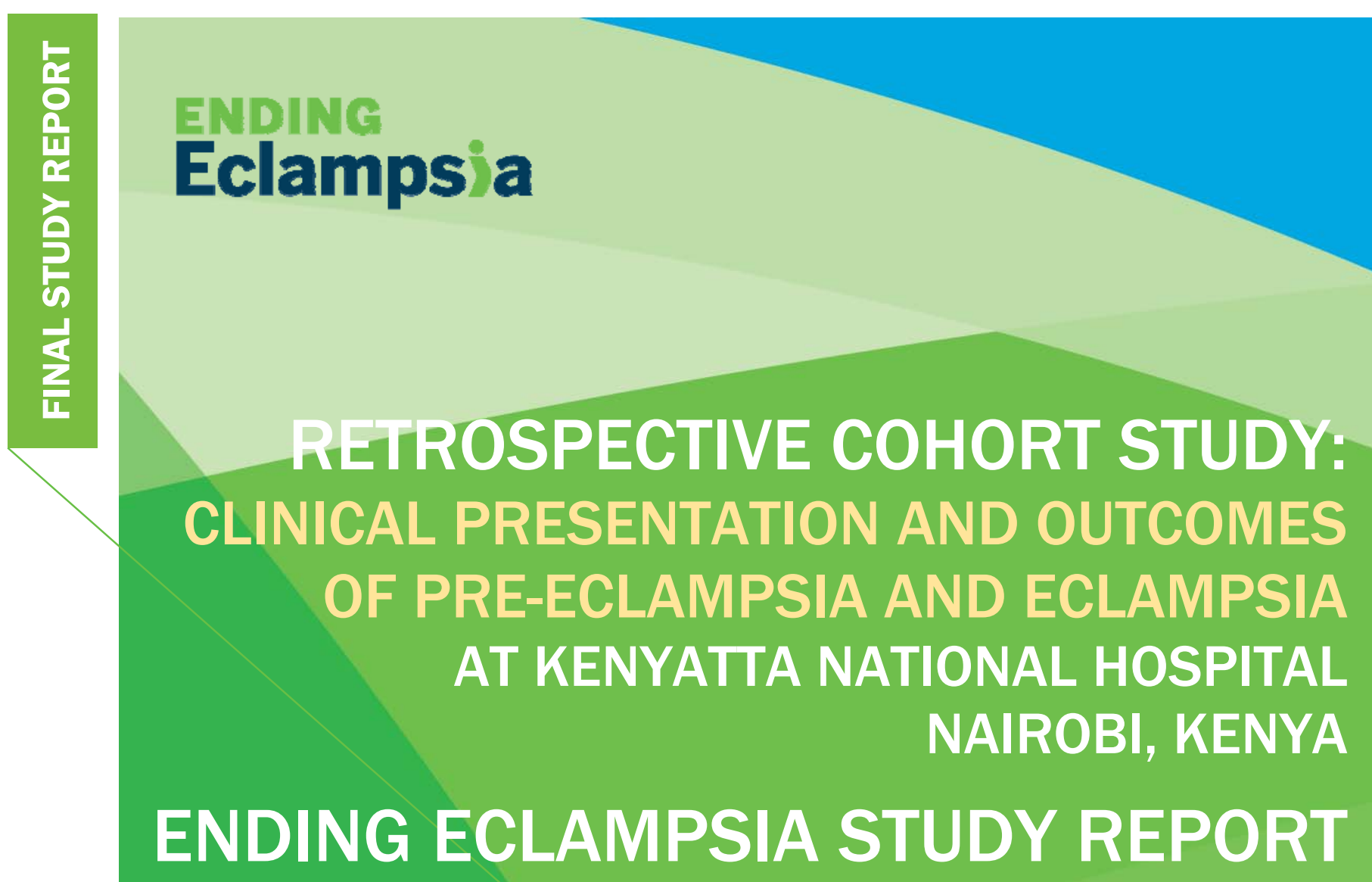

Charity Ndwiga, Alfred Osoti, Sripad Pooja, George Odwe, Omondi Ogutu, Warren Charlotte

February 2018 
Ending Eclampsia seeks to expand access to proven, under-utilized interventions and commodities for the prevention, early detection, and treatment of pre-eclampsia and eclampsia and strengthen global partnerships.

\section{- POPULATION COUNCIL \\ Idaes Eidence Irnpact.}

The Population Council confronts critical health and development issues-from stopping the spread of HIV to improving reproductive health and ensuring that young people lead full and productive lives. Through biomedical, social science, and public health research in 50 countries, we work with our partners to deliver solutions that lead to more effective policies, programs, and technologies that improve lives around the world. Established in 1952 and headquartered in New York, the Council is a non-governmental, non-profit organization governed by an international board of trustees.

Population Council

4301 Connecticut Avenue NW, Suite 280

Washington, DC 20008

Tel: +1. 877.237.9400

www.popcouncil.org

The study is made possible by the generous support of the American people through the United States Agency for International Development (USAID) under the terms of USAID APS-OAA-14-00048. The contents of this report are the sole responsibility of the Ending Eclampsia project and Population Council and do not necessarily reflect the views of USAID or the United States Government.

(c) 2018 The Population Council, Inc. 


\section{Acknowledgements}

We acknowledge the Departments of Obstetrics and Gynecology at the University of Nairobi (UoN) and Kenyatta National Hospital (KNH) and the Health Records and Clinical Research Department for leading the data collection, management, and analyses presented in this report. Specifically, we would like to thank research assistants at KNH, Dr. Brian Liyayi Nerea Ojanga, Raheli Mukwhana, Alice Nginyangi, Edith Gicheha, Catherine Mukhwati and Evalyne Chagina for their tireless efforts and contributions to data collection. We acknowledge Arnold Asava at the Population Council for his support in data quality assurance and analysis. We are grateful for the feedback provided by experts at $\mathrm{KNH}$ and UoN during the dissemination of preliminary findings as well as the National Maternal Health Technical Working Group for feedback at early stages of the project. We acknowledge USAID colleagues for their review of earlier versions of these findings and inputs to strengthen this report. 


\section{Table of Contents}

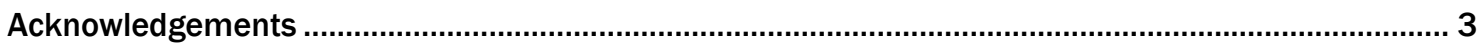

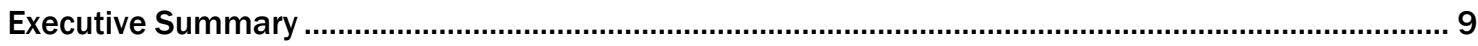

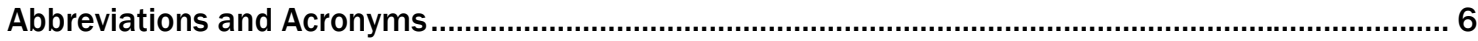

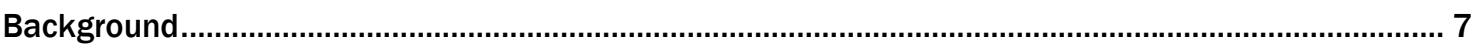

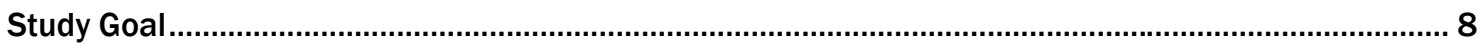

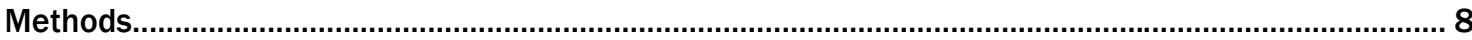

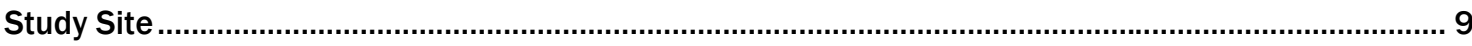

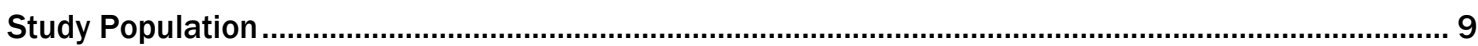

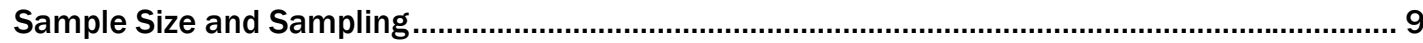

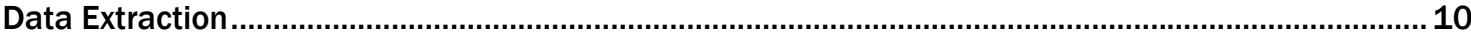

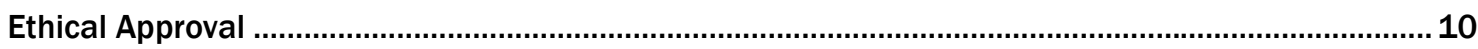

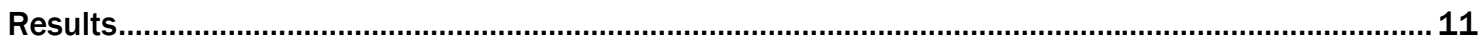

Socio-demographic Characteristics ....................................................................................... 11

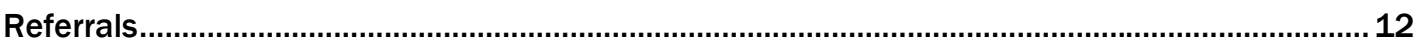

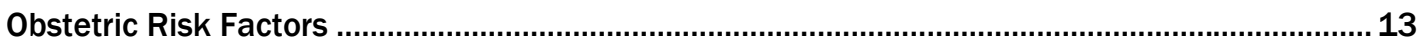

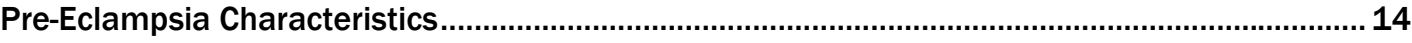

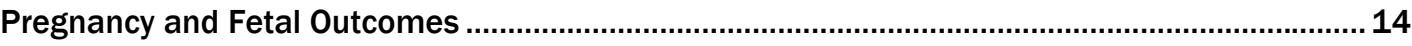

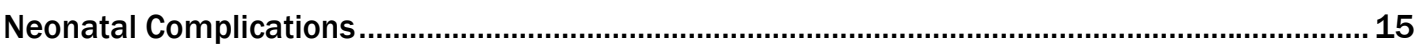

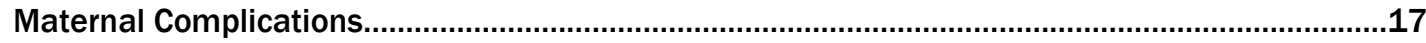

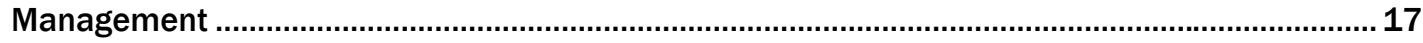

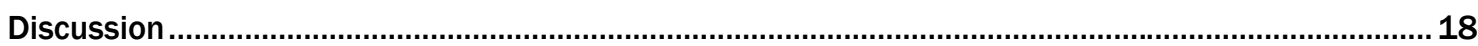

Limitations

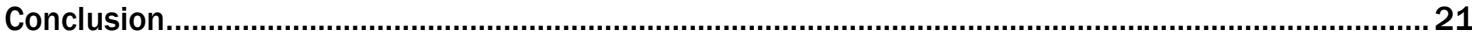

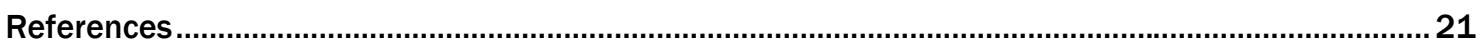

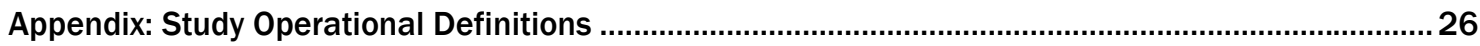




\section{Executive Summary}

It is increasingly recognized that pre-eclampsia has two distinct sub-types, depending on the timing of onset: early onset pre-eclampsia, which occurs before 34 weeks of gestation, and late onset preeclampsia, which occurs after 34 weeks. Few studies, however, examine and compare early and late onset pre-eclampsia in a low- and middle-income country setting.

This study's goal was to establish a profile of patients with hypertensive disorders in pregnancy, especially pre-eclampsia and eclampsia, over a two year period. At Kenya's national referral hospital, we examined clinical presentation at admission, management of complications, along with maternal and newborn health outcomes in the hospital's busy maternity unit, to ascertain any differences in health outcomes for early and late onset pre-eclampsia. De-identified maternity in-patient records were retrospectively reviewed for 620 women who received care for pre-eclampsia $(n=429)$ or eclampsia ( $n=191$ ), along the pregnancy continuum and up to 12 weeks' postpartum. All eclampsia records were included, along with every third pre-eclampsia record, stratified by month and year, for the period between September 2015 and October 2017. We recorded, for example, time of diagnosis of pre-eclampsia or eclampsia and time of any intervention, such as Caesarean section, to measure aspects of care. Maternity unit records, of admission to adult intensive care or newborn intensive care units, prolonged hospitalization, and maternal and perinatal or neonatal mortality, were utilized to assess the maternal and perinatal outcomes of interest: Specific maternal outcomes include eclampsia, dialysis, cerebrovascular accident, and other end organ damage; fetal and neonatal outcomes included stillbirth, low birth weight, prematurity, respiratory distress syndrome, necrotizing enterocolitis, neonatal jaundice, and convulsions.

Descriptive statistics and bivariate analyses employed Stata ${ }^{\circledR}$ 13. Statistical tests such as Chi-square and t-test tested for associations between women with early versus late onset of pre-eclampsia.

This study's findings show that out of the 620 records reviewed, 44 percent $(n=273)$ of pre-eclamptic and eclamptic women exhibited early onset of pre-eclampsia, while 56 percent had late onset. Nearly one quarter $(23 \%, n=126)$ of these women were referred from other facilities.

Women with early onset of pre-eclampsia (compared to late onset) have greater odds of adverse maternal and perinatal outcomes including hemolysis elevated liver enzymes and low platelets (HELLP) syndrome (OR: 4.34; 1.99-10.19; $p<0.001$ ), renal dysfunction (OR; 1.68; 20.71-4.1; $p<0.001)$, stillbirth (OR=4.96; 3.10-8.05; $p<0.001)$, and neonatal death (OR: 8.51; 3.82-21.37; $p<0.001$ ). Neonates born after early onset of pre-eclampsia had increased odds of respiratory distress (OR=16.99; 9.02-32.28; $p<0.001$ ) and birth asphyxia (OR: 1.89; 0.70-4.79; $p<0.142$ ). Results also associate early onset of pre-eclampsia with higher odds of prolonged maternal hospitalization, beyond seven days $(\mathrm{OR}=5.76 ; 3.94-8.42 ; \mathrm{p}<0.001)$, and antepartum hemorrhage $(\mathrm{OR}=5.80 ; 1.14-56.40 ; \mathrm{p}<0.001)$.

The profiles and outcomes of women with early onset of pre-eclampsia (compared to late onset) suggest that seriousness of morbidity increases with earlier onset. Although not statistically significant, more deaths were reported from women presenting with late onset of pre-eclampsia-the majority of whom were referred to $\mathrm{KNH}$ with eclampsia.

Early detection, continuous monitoring, identification of risk factors, and prompt referral are critical in mitigating the serious consequences of pre-eclampsia and eclampsia. 


\section{Abbreviations and Acronyms}

\begin{tabular}{ll} 
ANC & Antenatal Care \\
BP & Blood Pressure \\
CPAP & Continuous Persistent Airways Pressure \\
CVA & Cerebrovascular Accident \\
Dept. Ob/Gyn & Department of Obstetricians and Gynecologists \\
Dept. RH & Department of Reproductive Health \\
EO-PE & Early Onset Pre-Eclampsia \\
HDP & Hypertensive Disorders of Pregnancy \\
HTN & Hypertension \\
ICU & Intensive Care Unit \\
IRB & Institutional Review Board \\
IUGR & Intrauterine Growth Retardation \\
KNH & Kenyatta National Hospital \\
LBW & Low Birth Weight \\
LMIC & Low- and Middle Income Country \\
LO-PE & Late Onset Pre-Eclampsia \\
MFM & Maternal-Fetal Medicine \\
MgSO & Magnesium Sulphate \\
MNH & Maternal and Newborn Health \\
MOH & Ministry of Health \\
N/MW & Nurses Midwives \\
NEC & Necrotizing Enterocolitis \\
NCU & Newborn Care Unit \\
NICU & Neonatal Intensive Care Unit \\
Ob/Gyn & Obstetricians and Gynecologists \\
PE/E & Pre-Eclampsia/Eclampsia \\
PHC & Primary Health Care \\
PNC & Postnatal Care \\
RDS & Respiratory Distress Syndrome \\
SGA & Small-for-Gestational-Age \\
SHO & Senior House Officer \\
USAID & Unith Organization \\
WHO & World Hency for International Development \\
\hline
\end{tabular}




\section{Background}

Globally, about five to 10 percent of women experience hypertensive disorders of pregnancy (HDP) 1 , making it the second leading cause of maternal mortality and morbidity. Most HDP case occur in lowand middle-income countries (LMICs) ${ }^{2,3}$. HDPs include pre-eclampsia and eclampsia, gestational hypertension, 'white coat' hypertension, chronic hypertension, and chronic hypertension with superimposed pre-eclampsia5,6. Pre-eclampsia-hypertension with proteinuria after 20 weeks' pregnancy gestation-complicates about five percent of pregnancies ${ }^{7}$. Nearly 99 percent of the estimated 70,000 to 80,000 annual maternal, and 500,000 annual perinatal, pre-eclampsia-related deaths occur in LMICs 3,4 .

Pre-eclampsia and eclampsia (PE/E) have a devastating effect on mothers, their fetuses, and neonates. Women with $\mathrm{PE} / \mathrm{E}$ suffer severe morbidity and mortality due to eclampsia, and placental abruption, pulmonary edema, acute renal failure, and other organ damages 6,8 . Infants of mothers with pre-eclampsia have approximately twice the risk of neonatal death, and increased risks of low Apgar scores, seizures, neonatal encephalopathy, and neonatal intensive care admission ${ }^{6,9}$. Mothers with pre-eclampsia who deliver before 37 weeks of pregnancy are likely to have babies with low birth weight ${ }^{10,11}$. Recent studies in sub-Saharan Africa have identified risk factors for PE/E that include: primi-parity and para $\geq 5$, low plasma vitamin $C$, low levels of vitamin $D$, chronic hypertension, family history of hypertension, along with low levels of education ${ }^{12,13}$.

Early detection and management of pre-eclampsia is essential. Effective antenatal care (ANC) includes early identification of women with pre-eclampsia ${ }^{14}$, with accelerated visits near and at term, in addition to self-referrals by well-informed women, better diagnostic and surveillance capacities, and highly specialized care. It also involves follow up and control of chronic and gestational hypertension, availability and correct administration of drugs, timely delivery with optimum neonatal care, and critical and intensive maternal care ${ }^{15-17}$. Pre-conception care and good ANC are the mainstays of prevention, and in situations where pre-eclampsia or eclampsia (PE/E) are detected early, an intensive and multi-disciplinary approach to care is recommended and encouraged ${ }^{18}$. Adherence to stricter treatment protocols for controlling hypertension in pregnancy, including pharmacologic therapy for women exhibiting blood pressure of $150 / 100$, has been shown to reduce pregnancy risks ${ }^{19}$. It is also important to emphasise close monitoring of pre-eclampsia in postnatal women, to prevent adverse outcomes ${ }^{20}$.

Managing pre-eclampsia requires sustained monitoring and care to prevent progression to eclampsia. If detected early, clinical management can reduce associated complications. This may apply more to early onset pre-eclampsia (EO-PE) ${ }^{21,22}$.

The 2014 confidential inquiry into maternal death in Kenya revealed that HDP is the third leading cause of maternal mortality, responsible for 20 percent of maternal deaths ${ }^{23}$. The prevalence of preeclampsia in Kenya is estimated at 5.6 percent to 6.5 percent, based on two 2007 studies at Nairobi's Kenyatta National (KNH) and Aga Khan hospitals ${ }^{24,25}$. The prevalence of PE/E in rural areas may be much higher.

It is increasingly recognized that pre-eclampsia has two distinct sub-types according to when onset occurs: early onset pre-eclampsia (EO-PE), before 34 weeks' gestation, and late onset pre-eclampsia (LO-PE), after 34 weeks. Early onset disease is associated with higher morbidities and worse outcomes $^{7,26}$. Improved maternal and perinatal outcomes, including prematurity, require prompt and effective care and, likely, early delivery for women with early onset disease. Pre-term births include all live births prior to 37 weeks' gestation, with extremely pre-term babies prior to 28 weeks, very preterm between 28 and 32 weeks, and moderate to late pre-term between 32 and 37 weeks ${ }^{17,27}$.

Few evaluations have examined LMIC prevalence or incidence of early versus late onset disease, including Kenya, where late presentation and poor management elsewhere may negatively affect 
outcomes. To better understand and improve care for women experiencing early and late onset $\mathrm{PE} / \mathrm{E}$, an understanding of the disease burden is required. We therefore examined Kenya's clinical spectrum, including presentation at admission, management of complications, and maternal and newborn health $(\mathrm{MNH})$ outcomes at the maternity unit of a national referral hospital.

\section{Study Goal}

The goal of this study was to determine the profile of PE/E patients, and examine the differences in characteristics and health outcomes between EO-PE and LO-PE-for women who received ANC, intrapartum care, or postnatal care (PNC) at the national hospital.

The study hypotheses, linked to the conceptual framework (Figure 1), were:

- No difference in MNH outcomes for women with EO-PE (<34 weeks) and LO-PE ( $>=34)$

- No difference in socio-demographic and reproductive health $(\mathrm{RH})$ characteristics of women who presented with EO-PE (<<34 weeks) and LO-PE ( $>=34)$.

- No difference in clinical management of women with EO-PE (<<34 weeks) and LO-PE (>=34).

Figure 1: Conceptual framework ${ }^{1}$

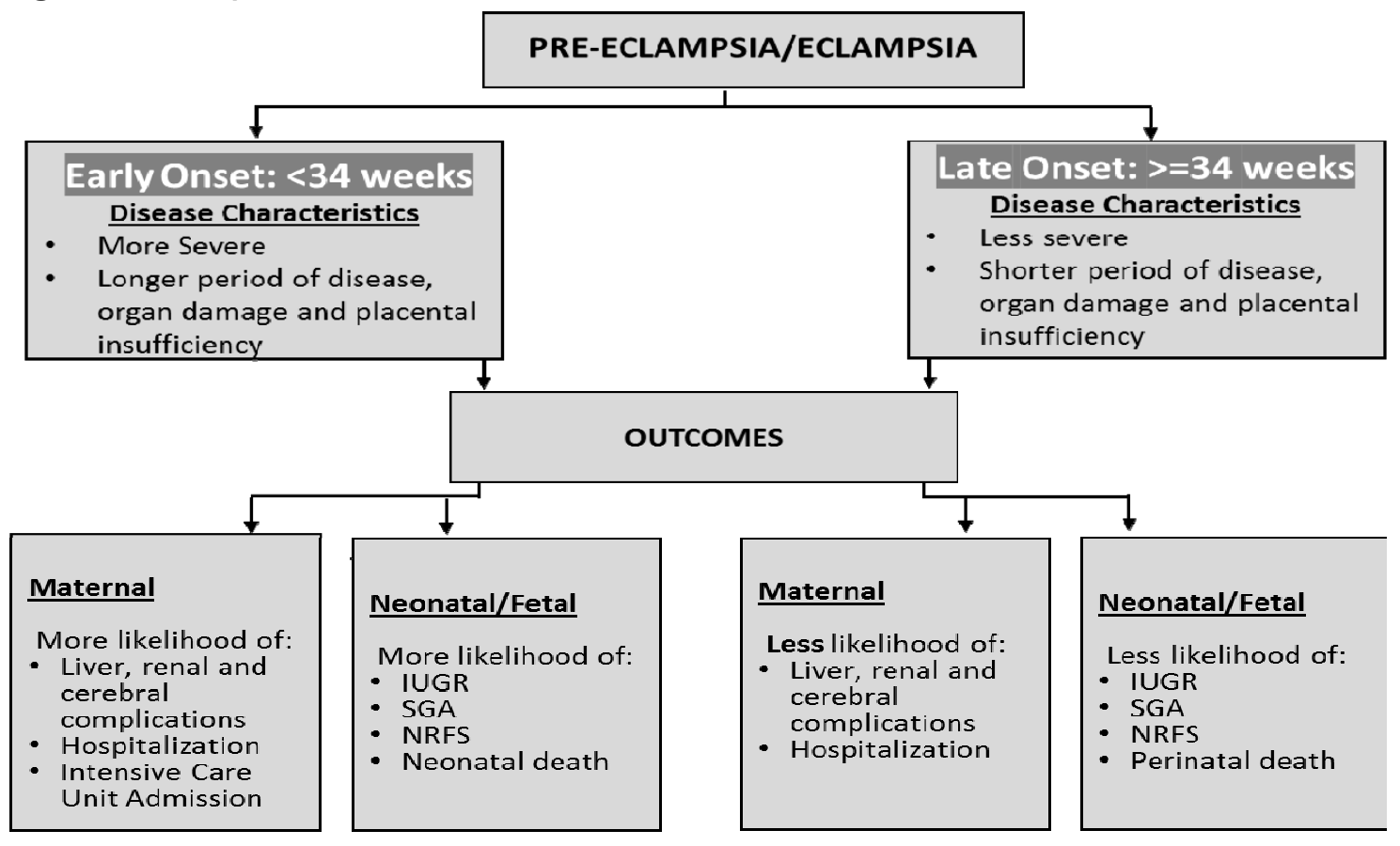

\section{Methods}

This is a retrospective cohort study design which examined socio-demographic characteristics, treatment, outcomes, and fetal and maternal complications among women with EO-PE and LO-PE. It draws on a review of de-identified records of women who attended ANC, intrapartum care, and PNC services and experienced pre-eclampsia, over a two year period (September 2015 to October 2017).

1 IUGR, Intrauterine growth restriction; SGA, Small-for-Gestational-Age; NRFS, Non-reassuring Fetal Status 


\section{Study Site}

This study was conducted at Kenyatta National Hospital $(\mathrm{KNH})$, the largest teaching and referral hospital in Kenya as well as East Africa. Located approximately three kilometers from Nairobi's central business district, with a capacity of 1,800 beds, $\mathrm{KNH}$ serves as a primary hospital for Nairobi County residents in addition to referred patients from different parts of Kenya. KNH's Reproductive Health (RH) Department of 220 beds is staffed by consultants, senior house officers, nurses, and midwives, and its maternity unit comprises an ANC clinic, labor ward (with 28 beds and 4 delivery couches), two maternity theatres (for Caesarean sections and other obstetrics procedures), and ANC ( 6 beds each) and PNC wards (12 beds each).

The maternity unit's newborn care unit (NBU) has 60 beds/incubators, and the neonatal intensive care unit (NICU) has five incubators/respirators. Sick babies born at $\mathrm{KNH}$, such as those with respiratory distress syndrome (RDS), low birth weight (LBW, less than two kilograms (kgs)), and birth asphyxia, among other complications, are taken directly to the NBU acute room, then reviewed by a neonatologist for NBU or NICU care, according to condition severity. Infants referred to KNH within 24 hours of birth, either from other facilities or those born before arrival or at home, are reviewed at the emergency/causality department and referred directly to NBU, while the mother is admitted to the PNC ward. Infants admitted to KNH more than 24 hours after delivery are admitted to the pediatric unit, which also have five intensive care unit (ICU) respirators/beds in addition to 60 beds.

About 100 babies are admitted per day to KNH's NBU, and stay for an average of 14 days. Healthy infants born to mothers with complications such as PE/E are not sent to NBU, with co-rooming encouraged if the mother is in a stable condition. If the mother continues to be unwell, relatives are advised to take the baby home after 24 hours, when possible. For low weight ( $2 \mathrm{~kg}$ to $2.4 \mathrm{~kg}$ ) or premature babies, kangaroo mother care $(\mathrm{KMC})$ is promoted if the mother's condition is stable.

The ANC clinic sees about 2,164 clients per month, and is staffed by consultants, senior house officers, and nurse/midwives. The labor ward operates 24 hours a day and conducts about 1,255 deliveries per month, and is staffed by a resident, senior house officer, medical officer, clinical officer interns, and nurse/midwives. Two daily major ward rounds are conducted by a consultant obstetrician/gynecologist (Ob/Gyn) every morning and evening. Pregnant and postnatal women with complications, including medical or surgical complications, receive multidisciplinary care either within the maternity unit or in other units. Any obstetric case transferred to another unit is managed by specialty and obstetric teams; for example, a mother with kidney failure or HELLP syndrome is managed by the nephrologist (kidney specialist) and obstetric teams.

\section{Study Population}

This study population comprises women who received ANC, intrapartum care, or PNC (up to 12 weeks following birth) at $\mathrm{KNH}$, or were referred to $\mathrm{KNH}$ preceding or following delivery elsewhere; only women who delivered at $\mathrm{KNH}$, or delivered elsewhere and were referred to $\mathrm{KNH}$, and suffered from $\mathrm{PE} / \mathrm{E}$ after 20 weeks' gestation were eligible. Eligibility criteria included PE/E diagnosis with high blood pressure, proteinuria, or evidence of end organ damage. Women who had hypertension but not $\mathrm{PE} / \mathrm{E}$ were excluded from the study.

\section{Sample size and sampling}

A two-proportion sample size calculation, to detect 30 percent difference with 95 percent confidence and 80 percent power ${ }^{28}$, accounting for missing cases, resulted in a sample of 620 women's records for review. The calculation was based on the main outcome: the incidence of adverse events after EO$\mathrm{PE}$ and LO-PE among pregnant or postnatal women presenting for care at $\mathrm{KNH}$ for the indexed 
pregnancy. Prior studies revealing EO-PE and LO-PE incidence rates of 0.38 percent and 2.7 percent, respectively; considering our high risk setting in a referral institution, we used incidence estimates of 0.4 percent EO-PE and four percent LO-PE to estimate our sample.

Of 1,529 eligible in-patient records identified, 191 (12.5\%) women experienced eclampsia and the remainder experienced pre-eclampsia. All eclampsia cases were included since the number was small. We then randomly sampled the inpatient records describing pre-eclampsia, stratified by month and year of observation resulting to 909 (59.5\%). After exclusion of a total of 480 (43.6\%) case files (due to missing or incomplete data), we achieved a sample of $620 \mathrm{PE} / \mathrm{E}$ case files for analysis. Figure 2 shows the study's sampling method and record review procedure for the study period.

Figure 2: Flow diagram of patient's records sample selection

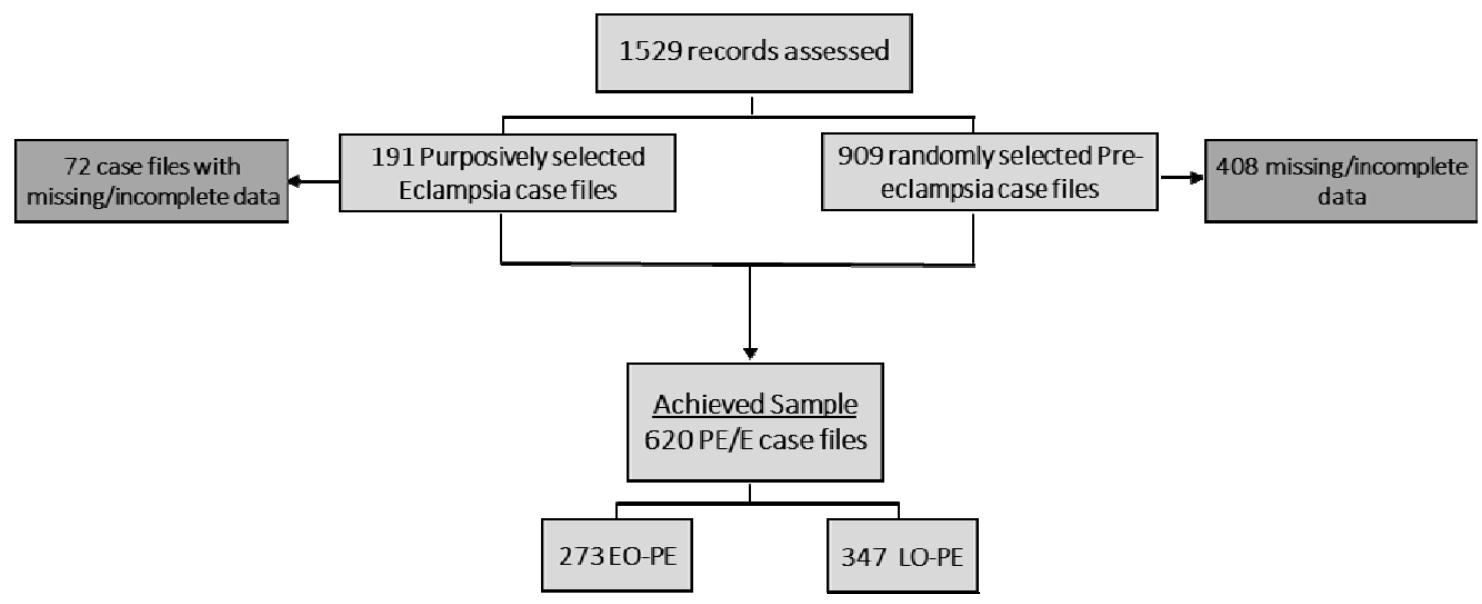

\section{Data Extraction and Analysis}

Two research assistants were trained to extract data from de-identified maternity inpatient records focusing on the time of diagnosis of $\mathrm{PE} / \mathrm{E}$ and the time of any treatment or intervention that enabled measurement of clinical management and care. Extractions assessed eligibility (EO-PE or LO-PE) by consensus review of the in-patient records and included: medical records, clinician notes or antenatal cards for any exposure in the month preceding delivery, gestational age by date, and ultrasound results. Data on MNH outcomes were also extracted. Maternal outcomes included eclampsia, cerebral vascular accident (CVA), other organ damage, dialysis, prolonged hospitalization admission including high dependency or ICU, and mortality. Perinatal outcomes included low birth weight, prematurity, respiratory distress syndrome, jaundice, admission to NCU and/or NICU, and mortality,

Descriptive statistics (frequency and percentage) and measures of central tendency (mean, standard deviations, median) are reported. We used chi square, t-test, and calculated odds ratio to determine any significant differences between the EO-PE and LO-PE cohorts. Descriptive statistics and bivariate analysis compared maternal and neonatal outcomes using Stata ${ }^{\circledR} 13$.

\section{Ethical Approval}

This study protocol was approved by Population Council's research ethics Institutional Review Board, as Protocol 813, and the KNH-UoN Ethics and Research Committee, as Protocol 293/06/2017. We also received permission to collect data from $\mathrm{KNH}$ departments of research and clinical services, health information and records, and $\mathrm{RH}$ services. 


\section{Results}

\section{Socio-demographic characteristics}

Of 620 records reviewed, 44 percent ( $n=273 ; 45$ had eclampsia) exhibited EO-PE, while 56 percent ( $n=34 ; 74$ had eclampsia) had LO-PE. Of the 273 women presenting with EO-PE, 124 (45.4\%) were less than 30 weeks pregnant, and 149 (54.6\%) were between 30 to 33 weeks. For women presenting with LO-PE, 39 percent were of 34 to 36 weeks' gestation, with 61 percent more than 36 weeks. The mean gestation age for onset of pre-eclampsia is 29.1 weeks for EO-PE, compared to 37.3 weeks for LO-PE. Women with EO-PE were slightly older (mean 29.2, standard deviation (SD) 6.11 years) than those with LO-PE (mean 27.8 years, SD 6.34 years; $p<0.008$ ). Significantly more women with LO-PE delivered by Cesarean section. We were unable to get robust data on the gestation age at ANC booking due to missing data (information was not recorded in in-patient records). There were no significant differences between the two groups on socio-demographic characteristics of parity, marital status, education, work status, and place of residence (Table 1).

Table 1: Socio-demographic characteristics of study participants

\begin{tabular}{|c|c|c|c|c|c|c|c|}
\hline Characteristics & \multicolumn{2}{|c|}{ Early Onset (PE) } & \multicolumn{2}{|c|}{ Late Onset (PE) } & \multicolumn{2}{|c|}{ Total } & P-value \\
\hline \multicolumn{8}{|l|}{ Age (years) } \\
\hline & 273 & SD & 347 & SD & 620 & SD & \\
\hline Mean, SD & 29.0 & 6.1 & 28.0 & 6.4 & 28.0 & 6.3 & 0.008 \\
\hline Parity & & & & & & & \\
\hline & 273 & $\%$ & 347 & $\%$ & 620 & $\%$ & \multirow{5}{*}{0.06} \\
\hline 0 & 30 & 11.0 & 42 & 12.1 & 72 & 11.6 & \\
\hline 1 & 88 & 32.2 & 143 & 41.2 & 231 & 37.3 & \\
\hline 2 & 78 & 28.6 & 73 & 21.0 & 151 & 24.4 & \\
\hline $3+$ & 77 & 28.2 & 89 & 25.6 & 166 & 26.8 & \\
\hline \multicolumn{8}{|l|}{ Gravidity } \\
\hline & 273 & $\%$ & 347 & $\%$ & 620 & $\%$ & \multirow{5}{*}{$<0.001$} \\
\hline 1 & 72 & 26.4 & 150 & 43.2 & 222 & 35.8 & \\
\hline 2 & 80 & 29.3 & 83 & 23.9 & 163 & 26.3 & \\
\hline 3 & 66 & 24.2 & 59 & 17.0 & 125 & 20.2 & \\
\hline $4+$ & 55 & 20.1 & 55 & 15.9 & 110 & 17.7 & \\
\hline \multicolumn{8}{|l|}{ Formal Education } \\
\hline & 273 & $\%$ & 347 & $\%$ & 620 & $\%$ & \multirow{4}{*}{0.7} \\
\hline$<=$ Primary^ $^{\wedge}$ & 82 & 30.0 & 110 & 31.7 & 192 & 31.0 & \\
\hline Secondary & 112 & 41.0 & 133 & 38.3 & 245 & 39.5 & \\
\hline Tertiary & 79 & 28.9 & 104 & 30.0 & 183 & 29.5 & \\
\hline \multicolumn{8}{|l|}{ Employment } \\
\hline & 273 & $\%$ & 347 & $\%$ & 620 & $\%$ & \multirow{3}{*}{0.5} \\
\hline Employed† & 134 & 49.1 & 161 & 46.4 & 295 & 47.6 & \\
\hline Unemployed $\ddagger$ & 139 & 50.9 & 186 & 53.6 & 325 & 52.4 & \\
\hline \multicolumn{8}{|l|}{ Marital Status } \\
\hline & 273 & $\%$ & 347 & $\%$ & 620 & $\%$ & \multirow{3}{*}{0.3} \\
\hline Married & 220 & 80.6 & 291 & 83.9 & 511 & 82.4 & \\
\hline Single & 53 & 19.4 & 56 & 16.1 & 109 & 17.6 & \\
\hline \multicolumn{8}{|l|}{ Place of Residence } \\
\hline & 273 & $\%$ & 347 & $\%$ & 620 & $\%$ & \multirow{3}{*}{0.01} \\
\hline Nairobi & 205 & 75.1 & 289 & 83.3 & 494 & 79.7 & \\
\hline Others & 68 & 24.9 & 58 & 16.7 & 126 & 20.3 & \\
\hline \multicolumn{8}{|l|}{ Religion } \\
\hline & 273 & $\%$ & 347 & $\%$ & 620 & $\%$ & \multirow{3}{*}{0.5} \\
\hline Christian & 266 & 97.4 & 341 & 98.3 & 607 & 97.9 & \\
\hline Muslim & 7 & 2.6 & 6 & 1.7 & 13 & 2.1 & \\
\hline \multicolumn{8}{|l|}{ Mode of delivery } \\
\hline & 242 & $\%$ & 341 & $\%$ & 583 & $\%$ & \multirow{3}{*}{$<0.001$} \\
\hline Vaginal Delivery** & 97 & 40.0 & 87 & 25.5 & 184 & 31.6 & \\
\hline Caesarean Section & 145 & 60.0 & 254 & 74.5 & 399 & 68.4 & \\
\hline
\end{tabular}




\begin{tabular}{|l|l|l|l|l|l|l|l|}
\hline GA at onset, weeks & \multicolumn{1}{|l|}{$\mid$} & \multirow{2}{*}{$<0.001$} \\
\hline Mean (SD) & 273 & SD & 347 & SD & 620 & SD & $<$ \\
\hline
\end{tabular}

Significant results $(\mathrm{P}<0.05)$ in bold color; * $(\mathrm{n} / \mathrm{N} * 100)$; GA - Gestational Age; ^None and primary education; † Includes Business, self-employed; $\ddagger$ includes housewife; **includes spontaneous vaginal delivery, assisted delivery and breech delivery

\section{Referrals}

One fifth (20\%) of the women with PE/E were referred from outside $\mathrm{KNH}$ amounting to a total of 126 referrals: $20 \%$ were referrals from health facilities outside of Nairobi county and $80 \%$ from within Nairobi county. Most referrals were from Kiambu and Kajiado counties (see Figure 3)-likely due to their proximity to Nairobi county. Out of all the referrals into $\mathrm{KNH}(\mathrm{n}=126)$ there were more women with EO-PE $(n=68,54 \%)$ than women with LO-PE $(n=58,46 \%)$. Figure 3 shows geographically where women traveled from to reach $\mathrm{KNH}$ in Nairobi (shown as a red dot), with shades of orange indicating the counties from which women traveled and the number of women who came from each county.

\section{Figure 3: Number referred into $\mathrm{KNH}$, by county of residence and distance of referrals}

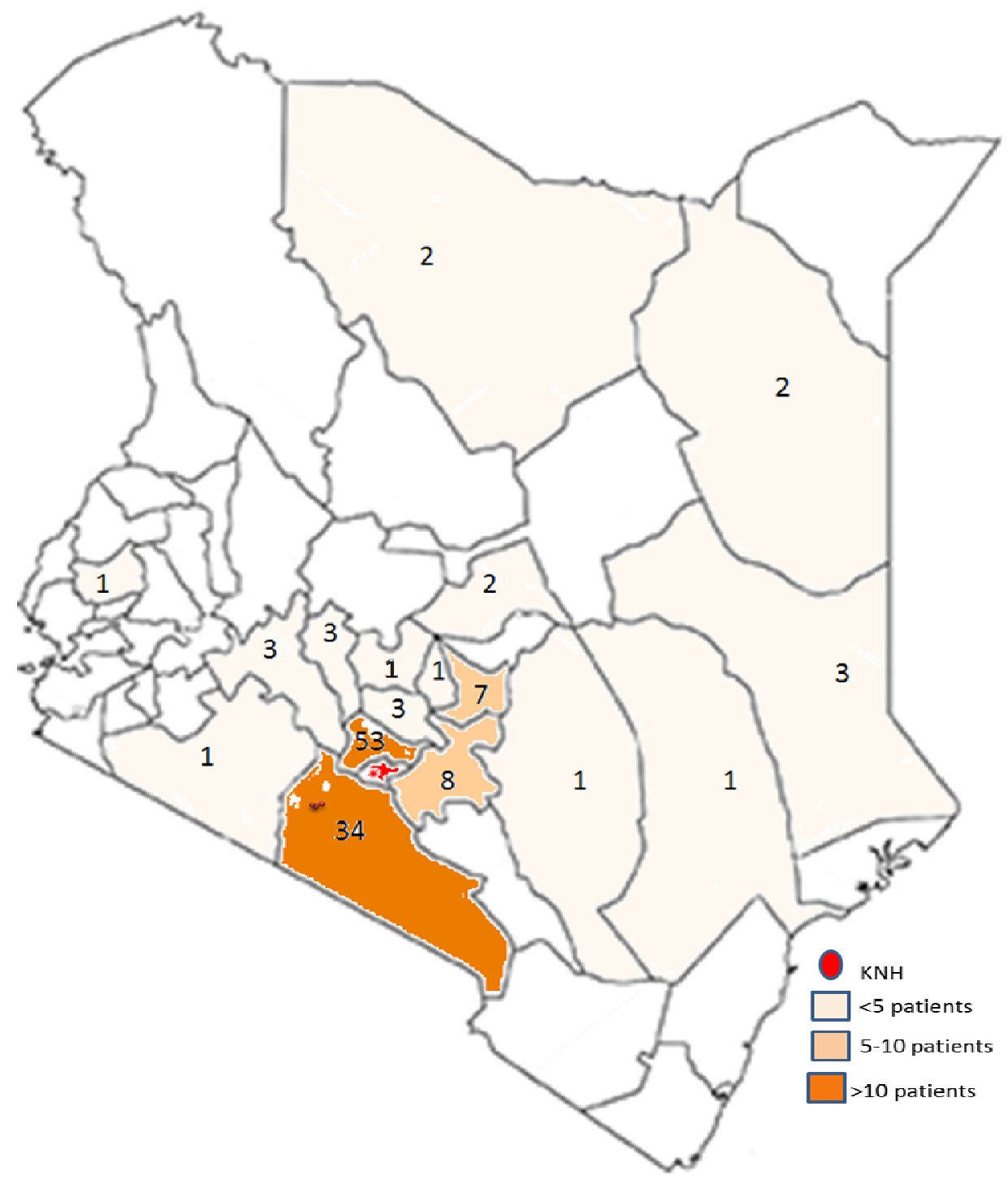




\section{Clinical presentation}

The majority of women experienced pre-eclampsia with severe complications, but women with EO-PE were more likely to experience pre-eclampsia with severe complications than women with LO-PE (see Figure 4). Eclampsia incidence was not associated with occurrence of pre-eclampsia onset.

Figure 4: $\mathrm{PE} / \mathrm{E}$ diagnosis

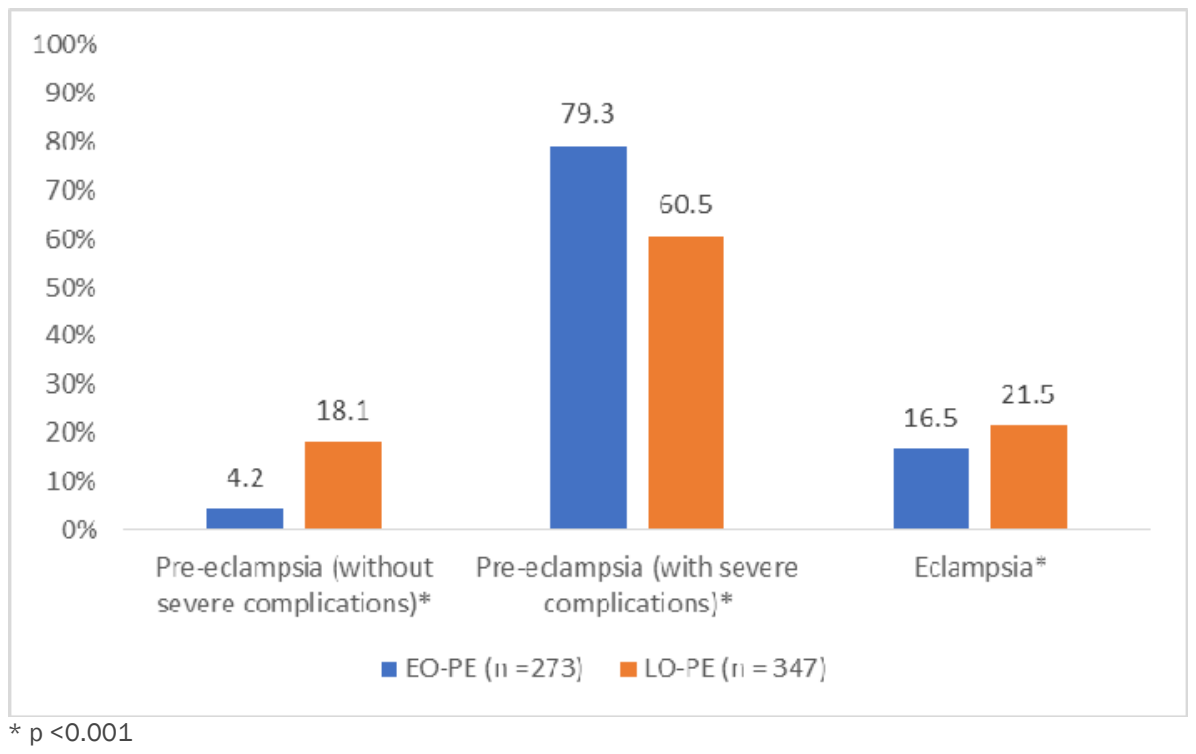

\section{Obstetric risk factors}

Figure 5 shows that women with EO-PE were more likely to have chronic hypertension or family history of hypertension compared to those with LO-PE. Prior experience of PE was also a major risk factor (1 in 10) for both EO-PE and LO-PE. Gestational diabetes mellitus and pre-gestational diabetes mellitus and prior eclampsia were less common overall $(<2 \%)$.

Figure 5: Obstetric risk factors by pre-eclampsia onset

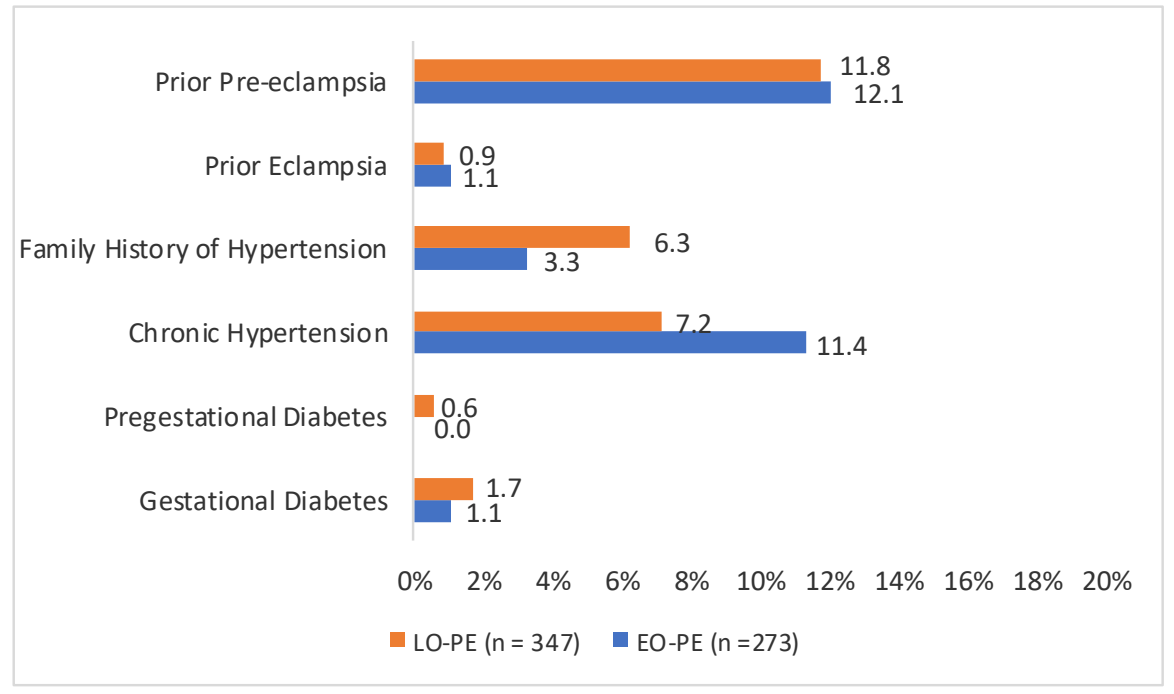




\section{Pre-eclampsia characteristics}

Table 2 shows the comparison between women with EO-PE and LO-PE based on the severity of their disease and blood results. Bivariate analysis show that women with EO-PE were more likely to experience severe pre-eclampsia, show highest systolic blood pressure (sBP, i.e. greater than 180 $\mathrm{mmHg}$ ), higher diastolic blood pressure (dBP), and lower creatinine than women with LO-PE. There were no differences by onset in experience of low haemoglobin and platelet levels $(<100000)$.

Table 2: Difference between two groups and severity of disease and blood results

\begin{tabular}{|c|c|c|c|c|c|}
\hline \multirow{2}{*}{$\begin{array}{l}\text { Severity of disease } \\
\text { and blood results }\end{array}$} & EO-PE $(n=273)$ & LO-PE $(n=347)$ & \multirow{2}{*}{ OR } & \multirow{2}{*}[95\%\mathrm{Cl}]{} & \multirow{2}{*}{ p-value } \\
\hline & $\mathrm{n}(\%)$ & $\mathrm{n}(\%)$ & & & \\
\hline Mild Pre-Eclampsia & $11(4.2)$ & $63(18.1)$ & 0.2 & 0.1 to 0.4 & $<0.001$ \\
\hline Severe Pre-Eclampsia & $217(79.3)$ & $210(60.5)$ & 2.5 & 1.7 to 3.7 & $<0.001$ \\
\hline Eclampsia & $45(16.5)$ & $74(21.5)$ & 0.7 & 0.5 to 1.1 & 0.16 \\
\hline Highest sBP >180 mmHG & $128(46.7)$ & $113(32.6)$ & 1.9 & 1.3 to 2.6 & $<0.001$ \\
\hline Lowest dBP $<90 \mathrm{mmHG}$ & $67(24.5)$ & $145(44.4)$ & 0.4 & 0.3 to 0.6 & $<0.001$ \\
\hline Highest SGOT (>70) & $77(28.2)$ & $130(37.5)$ & 0.7 & 0.5 to 0.9 & 0.02 \\
\hline Highest Creatine (>100) & $160(58.6)$ & $274(79.9)$ & 0.4 & 0.3 to 0.5 & $<0.001$ \\
\hline Lowest HB levels $(<10)$ & $18(6.7)$ & $30(9.5)$ & 0.7 & 0.4 to 1.4 & 0.34 \\
\hline Lowest Platelets $(<100000)$ & $68(24.9)$ & $110(31.7)$ & 0.7 & 0.5 to 1.0 & 0.06 \\
\hline
\end{tabular}

SGOT - serum glutamic-oxaloacetic transaminase; OR - Odds Ratio; $\mathrm{Cl}$ - Confidence Interval

\section{Pregnancy and fetal outcomes}

Of the 583 women whose delivery information was recorded, 399 (68\%) had a Caesarian section (csection), of whom 74 (18.5\%) had eclampsia. Additionally, 36.3 percent $(n=145)$ of all c-sections were among EO-PE women, and 63.7 percent $(n=254)$ were LO-PE (see Table 1). Mean gestational age at delivery was lower for EO-PE mothers (30.5 weeks) than LO-PE mothers (37.4 weeks) $(p<0.001)$.

Live births were more frequent among LO-PE women (91\%) than EO-PE women (62\%). More stillbirths and neonatal deaths occurred among EO-PE women than those with LO-PE (Figure 6). PE/E was associated with perinatal/neonatal death $(p<0.002)$, and more neonatal deaths occurred among infants of EO-PE mothers $(P<0.001)$ than among LO-PE mothers. No statistically significant difference in neonatal deaths was found for EO-PE or LO-PE women $(p=0.8)$ for the three PE/E categories (mild pre-eclampsia, severe pre-eclampsia, eclampsia), and there was also no statistically significant association between highest SBP and neonatal death $(p=0.15)$ or stillbirth $(p=0.8)$, in both arms.

\section{Figure 6: Fetal outcomes}

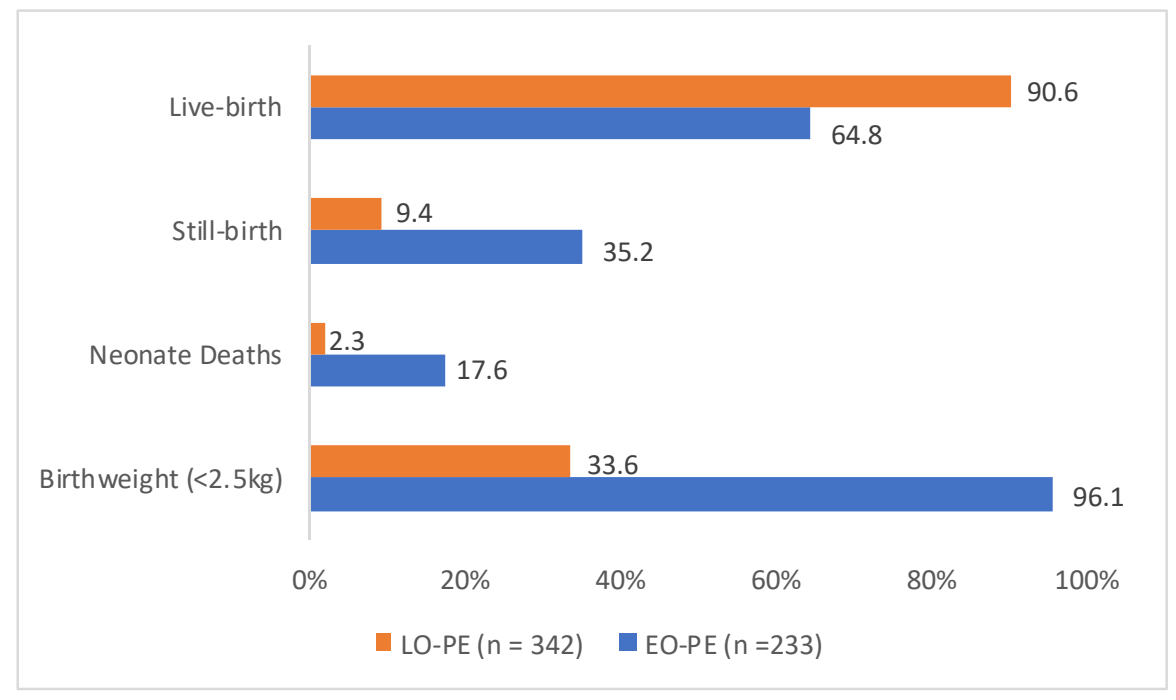


Birth weight analysis shows that most babies (63.1\%) born to EO-PE mothers weighed from one to two kilograms (kgs), while half $(50.0 \%)$ of those born to LO-PE mothers were between two and three kgs. Overall, babies of EO-PE mothers had lower birth weights than those of LO-PE mothers $(p<0.001)$.

Most pre-term deliveries were moderate to late ( $>32$ to 37 weeks), but more 'very pre-term' (28 to 32 weeks) and 'extremely pre-term' $(<28$ weeks) deliveries were among EO-PE women $(p<0.001)$.

\section{Figure 7: Pre-term deliveries among EO-PE and LO-PE women}

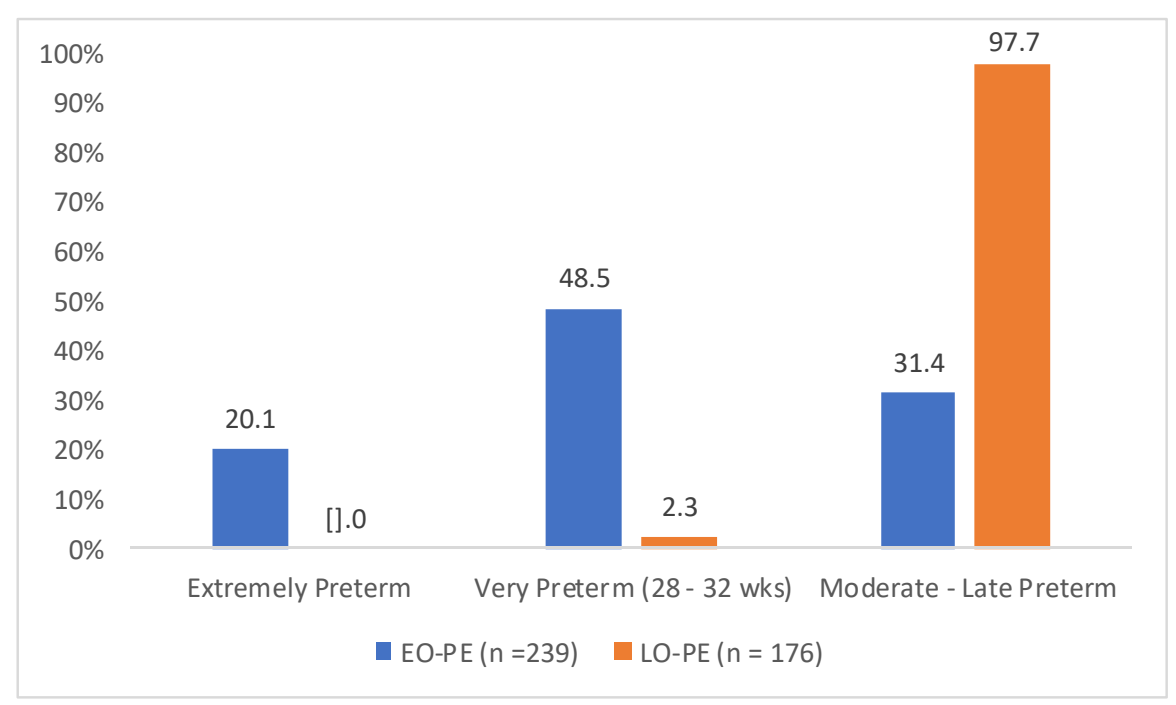

*Fisher's exact test used when $n<5$

\section{Newborn unit and NICU admissions}

A higher proportion of newborns $(n=133 ; 55 \%)$ of women with EO-PE were admitted to the NBU compared to newborns $(n=83 ; 24 \%)$ of women with LO-PE $(p<0.001)$. Only four neonates were admitted to NICU (2 per group). Table 4 shows the birthweight of all infants admitted to the NBU. It can also be observed that the majority of newborns from women with EO-PE and admitted at the NBU had lower birth weight compared to those of women with LO-PE.

Table 3: Showing birthweight categories of neonates admitted in the Newborn Unit

\begin{tabular}{|c|c|c|c|c|}
\hline \multirow{2}{*}{ Birth weight (kg) } & EO-PE $(n=133)$ & LO-PE $(n=83)$ & \multirow{2}{*}{ Total $(n=216)$} & \multirow{2}{*}{ P-value* } \\
\hline & $n(\%)$ & $n(\%)$ & & \\
\hline$<=1 \mathrm{~kg}$ & 25 (18.8) & $0(0.0)$ & 25 (11.6) & \multirow{5}{*}{0.004} \\
\hline$>1$ to $2 \mathrm{~kg}$ & 97 (72.9) & 29 (34.9) & $126(58.3)$ & \\
\hline$>2$ to $3 \mathrm{~kg}$ & $8(6.0)$ & $37(44.6)$ & $45(20.8)$ & \\
\hline$>3$ to $4 \mathrm{~kg}$ & $2(1.5)$ & 12 (14.5) & $14(6.5)$ & \\
\hline$>4 \mathrm{~kg}$ & $1(0.8)$ & $5(6.0)$ & $6(2.8)$ & \\
\hline
\end{tabular}

\section{Neonatal complications}

Neonatal complications reviewed include asphyxia, respiratory distress syndrome (RDS), neonatal jaundice, necrotizing enterocolitis (NEC), neonatal convulsions, and intraventricular haemorrhage (IVH). Compared to LO-PE mothers, neonates born of mothers who experienced EO-PE had significantly higher chances of having neonatal jaundice, RDS, and requiring breathing support through continuous positive airway pressure (CPAP). Birth asphyxia, NEC, and neonatal convulsions were also recorded among neonates of mothers with EO-PE (Figure 8, next page). 
Figure 8: Neonatal complications

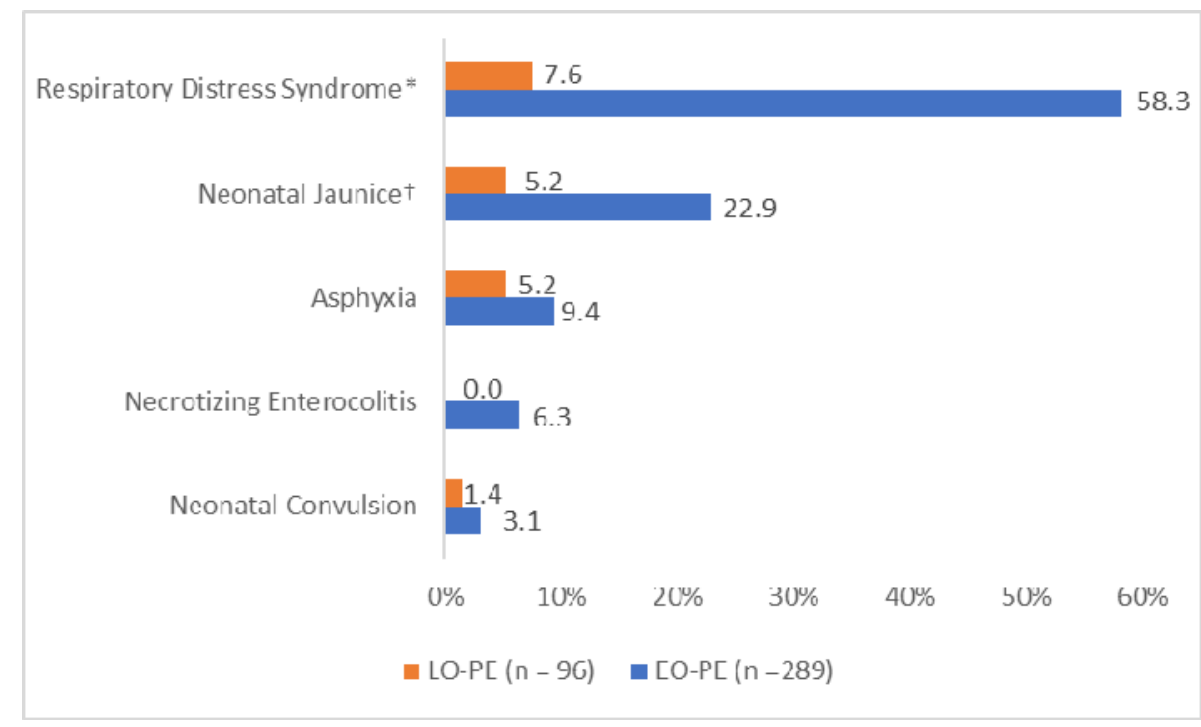

$* p<0.001 ; \uparrow p<0.01$

\section{Maternal complications}

Women with EO-PE were more likely than those with LO-PE to experience antepartum hemorrhage, hemolysis, elevated liver enzymes, and low platelet count (HELLP syndrome). In addition, women with EO-PE were more likely than those with LO-PE to be admitted for longer durations, due to complications. Few women experienced PPH, renal failure, or stroke (less than 6\%). Six women died (one presenting with EO-PE, and five presenting with LO-PE, Table 4), and all six were admitted at KNH in an eclamptic state. Four of the six women who died at $\mathrm{KNH}$ arrived in an eclamptic state during the early postnatal period. They had attended ANC, and delivered in other health facilities including a faith-based hospital, private maternity home, and health centers. Only one (EO-PE) of these deceased women was referred from outside Nairobi County. Three of the women who died had received a prereferral dose $\mathrm{MGSO}_{4}$.

\section{Table 4: Maternal complications}

\begin{tabular}{|c|c|c|c|c|}
\hline \multirow[t]{2}{*}{ Maternal Complications and Mortality } & $\begin{array}{c}\text { EO-PE } \\
(n=232)\end{array}$ & $\begin{array}{c}\text { LO-PE } \\
(n=341)\end{array}$ & \multirow[t]{2}{*}{ OR } & \multirow[t]{2}{*}{$\mathrm{Cl}$} \\
\hline & n (\%) & n (\%) & & \\
\hline Antepartum Hemorrhage- $\dagger$ & $8(3.3)$ & $2(0.6)$ & 5.80 & 1.1 to 56.8 \\
\hline HELLP* & $29(13.0)$ & $10(3.0)$ & 4.34 & 2.0 to 10.1 \\
\hline Postpartum Hemorrhage & $9(3.7)$ & $15(4.4)$ & 0.84 & 0.32 to 2.1 \\
\hline Renal Failure & $14(5.8)$ & $12(3.5)$ & 1.68 & 0.71 to 4.1 \\
\hline Cerebral Vascular Accident (CVA)/Stroke & $4(1.7)$ & $3(0.9)$ & 1.89 & 0.32 to 13.0 \\
\hline Retinal Detachment/Blindness & $0(0.0)$ & $0(0.0)$ & N/A & N/A \\
\hline Disseminated Intravascular Coagulation (DIC) & $0(0.0)$ & $2(0.6)$ & $\mathrm{N} / \mathrm{A}$ & N/A \\
\hline Pulmonary Edema & $0(0.0)$ & $1(0.3)$ & $\mathrm{N} / \mathrm{A}$ & N/A \\
\hline Deep Vein Thrombosis & $0(0.0)$ & $2(0.6)$ & N/A & N/A \\
\hline Dialysis & $8(3.0)$ & $6(2.0)$ & 1.90 & 0.6 to 6.6 \\
\hline Transfusion & $24(9.9)$ & $23(6.7)$ & 1.52 & 0.8 to 2.9 \\
\hline ICU High Dependency Unit & $8(3.0)$ & $10(3.0)$ & 1.13 & 0.4 to 3.2 \\
\hline Prolonged Hospital Stay > 1 week* & $155(67.0)$ & $81(24.0)$ & 5.72 & 3.9 to 8.4 \\
\hline Death & $1(0.4)$ & $5(2.0)$ & 0.28 & 0.01 to 2.5 \\
\hline
\end{tabular}

Significant results (If Cl does not include 1) in bold color; N/A - not available due to fewer/no cases; OR - Odds Ratio; $\mathrm{Cl}$ - Confidence Interval. Analysis excludes 37 women discharged at ANC. 


\section{Management}

Women with EO-PE and LO-PE received treatment with various anti-hypertensive drugs. The most widely used medicine for treatment among women with EO-PE and LO-PE was alpha methyldopa (aldomet) and nifedipine-given to over 80 percent of women with EO-PE and LO-PE, throughout the pregnancy continuum (ANC, labor and delivery, $\mathrm{PNC}$ ). Use of $\mathrm{MgSO}_{4}$ for managing pre-eclampsia was also common during the ANC period (EO-PE 60\%, LO-PE 51\%). Table 5 charts the use of antihypertensive drugs, $\mathrm{MgSO}_{4}$, and other drugs during ANC, labor and delivery, and PNC.

Table 5: Management of pre-eclampsia and eclampsia

\begin{tabular}{|l|c|c|c|c|c|c|}
\hline \multirow{2}{*}{ Drug } & \multicolumn{2}{|c|}{ ANC } & \multicolumn{2}{c|}{ Labor and Delivery* } & \multicolumn{2}{c|}{ PNC* $^{*}$} \\
\cline { 2 - 7 } & $\begin{array}{c}\text { EO-PE } \\
(\mathrm{n}=273)\end{array}$ & $\begin{array}{c}\text { LO-PE } \\
(\mathrm{n}=347)\end{array}$ & $\begin{array}{c}\text { EO-PE } \\
(\mathrm{n}=242)\end{array}$ & $\begin{array}{c}\text { LO-PE } \\
(\mathrm{n}=341)\end{array}$ & $\begin{array}{c}\text { EO-PE } \\
(\mathrm{n}=242)\end{array}$ & $\begin{array}{c}\text { LO-PE } \\
(\mathrm{n}=341)\end{array}$ \\
\hline Methyldopa (oral) & 94.9 & 83.3 & 95.0 & 84.2 & 95.0 & 86.5 \\
\hline Hydralazine (IV) & 25.3 & 9.5 & 14.1 & 5.3 & 8.7 & 4.4 \\
\hline Nifedipine (oral) & 94.1 & 79.5 & 93.8 & 81.8 & 92.2 & 85.9 \\
\hline Labetalol (oral) & 3.7 & 1.7 & 1.7 & 0.0 & 1.7 & 0.0 \\
\hline MgSO4 & 60.1 & 51.3 & 40.9 & 39.0 & 20.3 & 26.1 \\
\hline Diazepam & 1.1 & 0.0 & 0.0 & 0.6 & 0.4 & 0.6 \\
\hline Phenytoin & 1.8 & 0.3 & 0.8 & 0.6 & 2.1 & 1.8 \\
\hline Lasix & 3.7 & 0.9 & 2.5 & 1.2 & 5.4 & 1.2 \\
\hline Junior Aspirin & 5.5 & 0.9 & 0.4 & 0.0 & 0.0 & 0.0 \\
\hline
\end{tabular}

IV, Intravenous. *Analysis excludes 37 women discharged at ANC

Few (5.5\%) women received aspirin prophylaxis-which is recommended after 12 weeks' gestation for women at high risk of developing pre-eclampsia. Only three percent of women received calcium supplements during pregnancy-which are recommended for women with a low calcium diet, to prevent complications associated with pre-eclampsia. 


\section{Discussion}

This study set out to review in-patient records of 620 women who were treated for pre-eclampsia $(n=429)$ or eclampsia $(n=191)$ at Kenyatta National Hospital. Patient records were divided into two groups: those women who presented with EO-PE and those who presented with LO-PE. There are notable distinctions in the clinical presentation and management between EO-PE and LO-PE observed in this study, which helps contribute to the reduction of the knowledge gap for this complex maternal and fetal medical condition in low-resource settings.

The two arms differed significantly-for age, gravidity, residence, and delivery modes. Women with EOPE were slightly older than those with LO-PE, and more women with LO-PE had a higher gravidity than those with EO-PE. Maternal age and gravidity are implicated as pre-eclampsia risk factors ${ }^{29}$.

\section{Referrals}

Around one fifth of women diagnosed with PE/E (20\%) were referred to KNH from outside Nairobi County, most from neighboring counties, although a few traveled from distant locations. Five of the six deaths were among women who arrived at $\mathrm{KNH}$ in an eclamptic state; four arrived during the early postnatal period, after ANC and delivery services elsewhere. Three of the women who died had a prereferral dose of $\mathrm{MGSO}_{4}-$ although it is unclear when, and the women's conditions before receiving it. A study in Tanzania showed a higher risk of maternal mortality among eclamptic patients when they presented in a critically ill or moribund state ${ }^{30}$. In other studies, most patients received at a referral hospital with eclampsia had not received ANC or had received poor management in lower level facilities, with poor fetal and maternal outcomes ${ }^{31,32}$. These results lend credence to the importance of early referral for PE/E patients.

\section{Obstetric risk factors}

Factors such as previous $\mathrm{PE} / \mathrm{E}$ and chronic hypertension may confer higher risk for EO-PE, as opposed to LO-PE. Similar to other studies ${ }^{17,33,34}$, our study shows that more women who experience LO-PE have gestational diabetes and a family history of hypertension, and women with EO-PE have higher rates of chronic hypertension.

\section{Pre-eclampsia risk factors}

Severe pre-eclampsia, high SBP (>180), and high creatinine levels were all associated with EO-PE. Almost half of EO-PE women had SBP over $180 \mathrm{mmHg}$, while just over one third of LO-PE women had similar blood pressure rates, and the majority in both groups experienced severe pre-eclampsia-but more often among EO-PE women, similar to other studies ${ }^{34-37}$. There was no significant difference between the two cohorts of women (EO-PE versus LO-PE) for severity of pre-eclampsia in our study.

\section{Pregnancy and fetal outcomes}

A high proportion of pregnancies (more than two thirds) resulted in c-section-with significantly more among women with LO-PE (75\%) than with EO-PE (60\%). Evidence from other studies comparing outcomes for infants born to EO-PE women, through vaginal or c-section delivery, is weak ${ }^{38}$. Obstetricians usually face challenges in determining optimal mode of delivery for PE/E patients because there is no difference in delivery outcomes 39,40 . Our study shows no significant difference in outcomes between infants born via c-section or by spontaneous vaginal delivery. 


\section{Neonatal outcomes and complications}

The data also show that women with EO-PE were more likely to have poor fetal outcomes, resulting in stillbirth, low birth weight, premature birth, or infants with complications. Babies born to EO-PE women were more likely to experience respiratory distress syndrome, necrotizing enterocolitis, and neonatal jaundice than those whose mothers had LO-PE. This resonates with other research finding impaired neonatal growth along with higher perinatal mortality and morbidity among EO-PE mothers than among non-PE as well as LO-PE women $35,41,42$.

\section{NICU/NBU admission}

There is a significant difference in NBU admission between infants born to EO-PE mothers and those of LO-PE mothers. A surprising proportion of heavier babies also experienced neonatal convulsions and were admitted to the NBU. Because $\mathrm{KNH}$ is a national referral hospital for the most complex cases, there is a relatively high proportion NICU infants, regardless of PE/E onset. This study aligns with a number of others showing higher rates of neonatal deaths, premature births, NICU admission, and severe neonatal morbidity for infants born to mothers with EO-PE43-45.

\section{Maternal complications}

More EO-PE women experienced HELLP syndrome and antepartum hemorrhage than LO-PE women. Sub-optimal management, particularly at earlier stages of pregnancy, can lead to death, as seen in this study's small sample of women who died. A health system approach, focused particularly on skilled provider availability, specifically midwives, with training in emergency obstetric and neonatal care (EmONC), in addition to facility preparedness for measuring blood pressure, effective blood pressure management, and close follow up throughout pregnancy, with timely referrals, can contribute to reductions in maternal (and newborn) deaths ${ }^{46-49}$.

Discontinuity in HDP management often occurs in the postnatal period, highlighting the need to build on studies reporting incidences of postnatal hypertension ${ }^{27,50}$. Satisfactory PNC includes careful clinical evaluation of blood pressure, among other postnatal vital signs, during the hospital stay, with delayed discharge if hypertension continues, in addition to women's awareness of danger signs, such as headache and dizziness, after they return home ${ }^{51,52}$.

\section{Treatment}

Early detection of pre-eclampsia is crucial to ensure patients start appropriate management, which includes providing information on dangers signs and follow up care 22,53. This study shows similar use of antihypertensives and $\mathrm{MgSO}_{4}$ among the two cohorts (e.g. EO-PE and LO-PE). Although we are unable to demonstrate whether the timing of these drugs had any effect on maternal and fetal outcomes, judicial use of antihypertensives for moderate to severe HDP can reduce PE/E complications during the antenatal and postnatal periods $9,17,27,49,54$.

\section{Limitations}

Our study was limited by its retrospective nature, and our findings need to be interpreted with caution. In certain cases, onset of pre-eclampsia may have occurred a few days before hospital referral or admission. The lag between onset of PE and diagnosis during referral or admission may have resulted in misclassifying some EO-PE as LO-PE.

Due to poor routine record-keeping (e.g. scant information on referral and clinical forms), we were unable to collect critical data that would have helped assess more of the clinical management aspects of referred patients, particularly drug dosages, their administration routes, and treatment. 
This information would have allowed better understanding of which women who were treated received a pre-referral loading dose of $\mathrm{MgSO}_{4}$, as well as other treatment or clinical management, and their effects on fetal and maternal outcomes.

It was also difficult to retrieve and match newborn files to those of their mothers due to the filing systems, which delaying data collection.

It would have been helpful to collect information on the proportions of EO-PE and LO-PE women who came to $\mathrm{KNH}$ with a live baby and those who had a stillbirth before arriving, to also understand variations and effects of pre-eclampsia management across the pregnancy continuum. 


\section{Conclusion}

Early onset of pre-eclampsia is associated with greater disease severity as well as adverse maternal and perinatal outcomes, but eclampsia during the postnatal period is more likely to have devastating maternal outcomes. It is critical to closely monitor women for danger signs, both at facilities and at their homes, throughout the pregnancy continuum. Relevant interventions during ANC and PNC contacts with mothers, such as screening and history-taking, blood pressure measurement, and effective use of antihypertensive, must be prioritized, which will effectively reduce poor maternal and newborn outcomes. There is an added need to improve provider awareness and capacities for detecting pre-eclampsia early in pregnancy, which may mitigate adverse outcomes.

These results recommend the need for a Hypertensive Disorders of Pregnancy Registry that will store the medical information of women diagnosed with HDP, with their family histories. It can serve as a resource for prospective observational and interventional studies at $\mathrm{KNH}$, in Kenya in general, and elsewhere, that will lead to improved prediction of the risk of $\mathrm{PE} / \mathrm{E}$, and help establish new treatment regimens. As the leading referral hospital in Kenya, KNH wants to develop an HDP response team, for better management of future clients as well as informing the national guidelines.

This study's results disclose that EO-PE ultimately had greater adverse effects on newborns than on LO-PE women. This outcome reveals pre-eclampsia's heterogeneous nature and that its onset is a crucial indicator for the disease's severity.

\section{Key Messages}

Early Detection: Both ANC and PNC are critical platforms for pre-eclampsia detection.

Provider and community awareness of PE/E danger signs and information, with access to functional blood pressure-measuring equipment, may enhance early identification.

Identifying Risk Factors: This study shows that chronic high blood pressure and family history of pre-eclampsia are important risk factors for pre-eclampsia. Providers', as well as pregnant women's and community members', knowledge of PE/E risk factors are important for its prevention and management.

Continuous Monitoring: Once pre-eclampsia is identified, it is important to monitor the woman continuously to avert the disease's serious fetal and maternal consequences, and progression to eclampsia.

Focus on PNC: Many deaths analyzed in the study were due to eclampsia identified during the PNC period, suggesting failure to identify pre-eclampsia during ANC or early $P N C$. In addition to prompt detection of $P E / E$, effective $P N C$ is critical in managing immediate $\mathrm{PE} / \mathrm{E}$ complications and well as counselling on $\mathrm{PE} / \mathrm{E}$ 's long-term consequences for both mother and baby

Record-keeping: In this study, records especially referral and clinical management notes of $\mathrm{PE} / \mathrm{E}$ were inadequately kept. While this is not peculiar for this study, adequate record keeping is essential for continuity of care and future references informing management, programs, and policy. 


\section{References}

1. Duley L. 2009. The Global Impact of Pre-eclampsia and Eclampsia. Semin Perinatol 33(3): 130137.

2. Khan KS, D Wojdyla, L Say, AM Gülmezoglu, PF Van Look. 2006. WHO Analysis of Causes of Maternal Death: A Systematic Review. Lancet 367(9516): 1066-1074.

3. Hutcheon JA, S Lisonkova, KS Joseph. 2011. Epidemiology of Pre-Eclampsia and the Other Hypertensive Disorders of Pregnancy. ScienceDirect [internet, cited 31 Aug '18]. www.sciencedirect.com/science/article/pii/S1521693411000198

4. Khan KS, D Wojdyla, L Say, AM Gülmezoglu, PF Van Look. 2006. WHO Analysis of Causes of Maternal Death: A Systematic Review. Lancet 367(9516): 1066-1074.

5. American College of Obstetricians and Gynecologists Task Force on Hypertension in Pregnancy. Hypertension in pregnancy. 2013. Report of the American College of Obstetricians and Gynecologists' Task Force on Hypertension in Pregnancy. Obstet Gynecol 122(5): 1122-1131.

6. Friedman SA, E Schiff, L Kao, BM Sibai BM. 1995. Neonatal Outcome After Preterm Delivery for Pre-Eclampsia. Am J Obstet Gynecol 172(6): 1785-1792.

7. Janani F and F Changaee. 2017. Seasonal Variation in Prevalence of Pre-Eclampsia. J Fam Med Prim Care 6(4): 766-769.

8. Paruk F and J Moodley. 2000. Maternal and Neonatal Outcome in Early- and Late-Onset PreEclampsia. Seminars in Neonatology. [internet, cited 31 Aug '18]. www.sfnmjournal.com/article/S1084-2756(00)90023-X/abstract

9. Von Dadelszen P, D Sawchuck, G Justus Hofmeyr, LA Magee, H Bracken, M Mathai et al. 2013. PRE-EMPT (Pre-Eclampsia-Eclampsia Monitoring, Prevention and Treatment): A Low and Middle Income Country Initiative to Reduce Global Burden of Maternal, Fetal and Infant Death and Disease Related to Pre-Eclampsia. Pregnancy Hypertens 3(4): 199-202.

10. Xiong X, NN Demianczuk, LD Saunders, FL Wang, WD Fraser. 2002. Impact of Pre-Eclampsia and Gestational Hypertension on Birth Weight by Gestational Age. Am J Epidemiol 155(3): 203-209.

11. Szymonowicz W and VY Yu. Severe Pre-Eclampsia and Infants of Very Low Birth Weight. Arch Disease Childhood. [internet, cited 7 Dec '18]. https://adc.bmj.com/content/62/7/712

12. Kiondo P et al. 2012. Risk Factors for Pre-Eclampsia in Mulago Hospital, Kampala, Uganda. Trop Med Intl Health 17(4): 480-487.

13. Bilano VL, E Ota, T Ganchimeg, R Mori, JP Souza. 2014. Risk Factors of Pre-Eclampsia/Eclampsia and Its Adverse Outcomes in Low- and Middle-Income Countries: WHO Secondary Analysis. PLoS One 19(3): e91198. [internet]. www.ncbi.nIm.nih.gov/pmc/articles/PMC3962376

14. Say L et al. 2014. Global Causes of Maternal Death: WHO Systematic Analysis. Lancet Glob Health 2(6): e323-333.

15. Pauli JM and JT Repke. 2017. Pitfalls with New American College of Obstetricians and Gynecologists Task Force on Hypertension in Pregnancy. Clin Obstet Gynecol 60(1): 141-152.

16. Say L et al. 2014. Global Causes of Maternal Death: WHO Systematic Analysis. Lancet Glob Health 2(6): e323-333.

17. Sulistyowati S. 2017. Early and Late Onset Preeclamsia: What Did Really Matter? J Gynecol Women's Health 5(4). https://juniperpublishers.com/igwh/pdf/JGWH.MS.ID.555670.pdf 
18. World Health Organization, ed. 2016. WHO Recommendations on Antenatal Care for Positive Pregnancy Experience. Geneva: World Health Organization, 152.

19. Kattah AG and VD Garovic. 2013. Management of Hypertension in Pregnancy. ScienceDirect [internet, cited 8 Nov '18]. www.sciencedirect.com/science/article/pii/S1548559513000281

20. Townsend R, P O'Brien, A Khalii. 2016. Current Best Practice in Management of Hypertensive Disorders in Pregnancy. Integr Blood Press Control 9: 79-94.

21. Mandade K, K Singh, DP Bhavthankar. 2017. Outcome of Expectant Line of Management in Early Onset (24-32 weeks) Pregnancy Induced Hypertension. Int J Repr Contracep Obstet Gynecol 6(5): 1932-1941.

22. Saisto T, A Tiitinen, VM Ulander, R Kaaja. 2004. Clinical Cure of Severe, Early Onset PreEclampsia with Low Molecular Weight Heparin Therapy in Primigravida with Hyperreactio Luteinalis and Thrombophilia. Human Repro 19(3): 725-728. [internet, cited 6 Nov '18]. https://academic.oup.com/humrep/article/19/3/725/658373

23. Ministry of Health Kenya. 2017. Saving Mothers' Lives 2017. First Confidential Report into Maternal Deaths in Kenya. Nairobi.

24. Kenyatta National Hospital. 2007. Prevalence of Hypertensive Diseases in Pregnancy at Kenyatta National Hospital, Kenya 2007. Nairobi.

25. Agha Khan University Hospital. 2007. Prevalence of Hypertensive Diseases in Pregnancy at Agha Khan University Hospital, Kenya 2007. Nairobi.

26. Tranquilli AL, MA Brown, GG Zeeman, GA Dekkere, BM Sibaif. 2013. Definition of Severe and Early-onset Pre-Eclampsia. Statements from International Society for Study of Hypertension in Pregnancy (ISSHP) [internet, cited 31 Aug '18]. https://doi.org/10.1016/j.preghy.2012.11.001

27. Brown MA, LA Magee, LC Kenny, SA Karumanchi, FP McCarthy, S Saito et al. 2018. Hypertensive Disorders of Pregnancy. Hypertension 72(1): 24-43.

28. Donner A. 1984. Approaches to Sample Size Estimation in Design of Clinical Trials: A Review. Stat Med 3(3): 199-214.

29. Duckitt $K$ and D Harrington. 2005. Risk Factors for Pre-Eclampsia at Antenatal Booking: A Systematic Review of Controlled Studies. BMJ 330(7491): 565.

30. Ndaboine EM, A Kihunrwa, R Rumanyika, HB Im Ahm. 2012. Maternal and Perinatal Outcomes Among Eclamptic Patients Admitted to Bugando Medical Centre, Mwanza, Tanzania. Afr J Repro Health 16(1): 35-41.

31. Gomathy E, A Lahari, R Kondareddy. 2018. Early Onset and Late Onset Pre-Eclampsia-Maternal and Perinatal Outcomes in a Rural Tertiary Health Center. Int J Rep Contracep Obstet Gynecol 7(6): 2266-2269. www.ijrcog.org/index.php/ijrcog/article/view/4744

32. Madazli R, MA Yuksel, M Imamoglu, A Tuten, M Oncul, B Aydin, G Demirayak. 2014. Comparison of Clinical and Perinatal Outcomes in Early- and Late-onset Pre-Eclampsia. Arch Gynecol Obstet 290(1): 53-57.

33. lacobelli S, F Bonsante, PY Robillard. 2017. Comparison of Risk Factors and Perinatal Outcomes in Early Onset and Late Onset Pre-Eclampsia: Cohort-based Study in Reunion Island.

ScienceDirect. [internet, cited 29 Aug '18]. www.sciencedirect.com/science/article/pii/S0165037817301857

34. Lisonkova S, KS Joseph. 2013. Incidence of Pre-Eclampsia: Risk Factors and Outcomes Associated with Early- Versus Late-onset Disease. Am J Obstet Gynecol 209(6): 544.e1-544.e12. 
35. Van Esch JJA, AF van Heijst, AFJ de Haan, OWH van der Heijden. 2017. Early-onset Pre-Eclampsia Is Associated with Perinatal Mortality and Severe Neonatal Morbidity. J Mat Fetal Neonat Med. [internet]. DOI: 10.1080/14767058.2016.1263295

36. You SH, PJ Cheng, TT Chung, CF Kuo, HM Wu, PH Chu. 2018. Population-based Trends and Risk Factors of Early- and Late-onset Pre-Eclampsia in Taiwan 2001-2014. BMC Preg Childbirth 18(1). [internet, cited 30 Aug '18]. https://bmcpregnancychildbirth.biomedcentral.com/articles/10.1186/s12884-018-1845-7

37. Gulec UK, FT Ozgunen, S Buyukkurt, AB Guzel, IF Urunsak, SC Demir et al. 2013. Comparison of Clinical and Laboratory Findings in Early- and Late-onset Pre-Eclampsia. J Mat Fetal Neonat Med 26(12): 1228-1233.

38. Alanis MC, CJ Robinson, TC Hulsey, M Ebeling, DD Johnson. 2008. Early-onset Severe PreEclampsia: Induction of Labor vs Elective Cesarean Delivery and Neonatal Outcomes. Am J Obstet Gynecol 199(3): 262.e1-262.e6.

39. Barros FC, ZA Bhutta, M Batra, TN Hansen, CG Victora, CE Rubens et al. 2010. Global Report on Preterm Birth and Stillbirth (3 of 7): Evidence for Effectiveness of Interventions. BMC Preg Childbirth 10(1): S3.

40. Duley L, S Meher, E Abalos. 2006. Management of Pre-Eclampsia. BMJ 332(7539): 463-468.

41. Dora SK, L Nayak, B Pande, AB Dandapat. 2017. Prospective Observational Study for Evaluation of Maternal and Fetal Outcomes in Patients with Eclampsia. Int J Res Med Sci 5(5): 1785-1789.

42. Kovo M, L Schreiber, O Elyashiv, A Ben-Haroush, G Abraham, J Bar. 2015. Pregnancy Outcomes and Placental Findings in Pregnancies Complicated by Fetal Growth Restriction with and Without Pre-Eclampsia. Repro Sci 22(3): 316-321.

43. Markin L and O Medvyedyeva. 2017. Early Versus Late-onset Pre-Eclampsia: Differences in Risk Factors and Birth Outcomes. Viv Clinical Bulletin 4(20): 30-34. [internet]. http://Ikv.biz/ISSN $\underline{2520-2898}$

44. lacobelli S, F Bonsante, PY Robillard. 2017. Comparison of Risk Factors and Perinatal Outcomes in Early Onset and Late Onset Pre-Eclampsia: Cohort-based Study in Reunion Island. J Repro Immunol 123: 12-16.

45. Van Esch JJA, AF van Heijst, AFJ de Haan, OWH van der Heijden. 2017. Early-onset Pre-Eclampsia Is Associated with Perinatal Mortality and Severe Neonatal Morbidity. J Matern Fetal Neonatal Med 30(23): 2789-2794.

46. Ishaku S, B Ahonsi, J Tukur, O Ayodeji. 2013. Attrition from Care after Critical Phase of Severe Pre-Eclampsia and Eclampsia: Insights from Intervention with Magnesium Sulphate in a Primary Care Setting in Northern Nigeria. Health 5(9): 1461-1466.

47. Renfrew J et al. 2014. Midwifery and Quality Care: Findings from New Evidence-informed Framework for Maternal and Newborn Care. ScienceDirect. [internet, cited 14 Jan '19]. www.sciencedirect.com/science/article/pii/S0140673614607893

48. Hanson C, J Cox, G Mbaruku, F Manzi, S Gabrysch, D Schellenberg et al. 2015. Maternal Mortality and Distance to Facility-based Obstetric Care in Rural Southern Tanzania: Secondary Analysis of Cross-Sectional Census Data in 226,000 Households. Lancet Glob Health 3(7): e387-395.

49. Duhig K, B Vandermolen, A Shennan. 2018. Recent Advances in Diagnosis and Management of Pre-Eclampsia. F1000Research 7. [internet, cited 15 Jan '19]. www.ncbi.nlm.nih.gov/pmc/articles/PMC5832913 
50. Bramham K, C Nelson-Piercy, MJ Brown, LC Chappell. 2013. Postpartum Management of Hypertension. BMJ 346: f894.

51. Magee L, P von Dadelszen. 2013. Prevention and Treatment of Postpartum Hypertension. Cochrane Database Syst Rev 4. [internet, cited 13 Nov '18].

www.cochranelibrary.com/cdsr/doi/10.1002/14651858.CD004351.pub3/abstract

52. Sibai BM. 2012. Etiology and Management of Postpartum Hypertension-Pre-Eclampsia. Am J Obstet Gynecol 206(6): 470-475.

53. Carter W et al. 2017. Narrative Synthesis of Factors that Affect Women Speaking up About Early Warning Signs and Symptoms of Pre-Eclampsia and Responses of Healthcare Staff. BMC Preg Childbirth. [internet, cited 13 Nov '18].

https://bmcpregnancychildbirth.biomedcentral.com/articles/10.1186/s12884-017-1245-4

54. James PR and C Nelson-Piercy. 2004. Management of Hypertension Before, During, and After Pregnancy. Heart 90(12): 1499-1504. 


\section{Appendix}

\section{Study operational definitions}

High blood pressure (BP) during pregnancy: BP of 140/90 mmHg or more measured on two consecutive times in a relaxed client, four hours apart, or a systolic BP measurement $\geq 160 \mathrm{mmHg}$ or a diastolic BP measurement after one measurement in a relaxed client.

Mild hypertension: Systolic BP 140 to $149 \mathrm{mmHg}$ and or diastolic BP 90 to $109 \mathrm{mmHg}$

Severe hypertension: Systolic BP $\geq 160 \mathrm{mmHg}$ and/or diastolic BP $\geq 110 \mathrm{mmHg}$

Chronic hypertension in pregnancy: Pre-existing hypertension, that predates the pregnancy.

Gestational hypertension: High BP with first onset after 20th week of pregnancy (second half of pregnancy) without associated significant proteinuria.

Pre-eclampsia: High BP (140/90 mmHg or higher) associated with significant proteinuria occurring for first time after second half of pregnancy (after 20 weeks' gestation) in a previously normal individual. Women with pregnancy-induced high BP, with albumin in urine, are defined as pre-eclamptic.

Severe pre-eclampsia: Severe pre-eclampsia is pre-eclampsia with severe hypertension and/or with symptoms, and/or biochemical and/or hematological impairment (NICE 2010).

a) Diastolic $B P \geq 110 \mathrm{mmHg}$ or systolic $\geq 160 \mathrm{mmHg}$ after two measurements, four hours apart, with albumin in urine; or

b) Diastolic BP is 90 to $109 \mathrm{mmHg}$ or systolic $\geq 160 \mathrm{mmHg}$ after two measurements, four hours apart, with albumin in urine and severe headache, and/or blurred vision, and/or pain in upper abdomen. This is now known as pre-eclampsia with severe features.

Eclampsia: Pregnancy-induced high BP (140/90 mmHg or greater), excess protein in urine and occurrence of generalized convulsions/seizures during pregnancy, labor or within 42 days of delivery in the absence of epilepsy or another condition predisposing to convulsions (Sibai BM, 2005)

Eclampsia occurs: $38 \%$ to $55 \%$ during pregnancy

$13 \%$ to $36 \%$ intrapartum

$5 \%$ to $39 \%$ within 48 hours of giving birth

$5 \%$ to $17 \%$ greater than 48 hours after birth.

Cerebrovascular accident (CVA) or stroke: Hemiparesis and/or blindness developed during pregnancy or in the 42 days postpartum lasting greater than 48 hours. CVA/Stroke implies sudden cessation of blood flow to brain cells either as a result of rupture or blockage of the supplying blood vessels leading to temporary or permanent loss of motor function, speech impairment, loss of memory and occasionally coma (prolonged unconsciousness for 12 or more hours) or death. 